\title{
Intoxicação por Crotalaria retusa (Fabaceae) em Eqüídeos no semi-árido da Paraíba1
}

\author{
Verônica Medeiros da Trindade Nobre², Franklin Riet-Correa², José Maria Barbosa \\ Filho $^{3}$, Antonio Flávio Medeiros Dantas ${ }^{2}$, Ivon Macedo Tabosa² e Jackson Silva \\ Vasconcelos ${ }^{2}$
}

\begin{abstract}
Nobre V.M.T., Riet-Correa F., Barbosa Filho J.M., Dantas A.F.M., Tabosa I.M. \& Vasconcelos J.S. 2004. [Poisoning by Crotalaria retusa (Fabaceae) in Equidae in the semiarid region of Paraíba.] Intoxicação por Crotalaria retusa (Fabaceae) em Eqüídeos no semi-árido da Paraíba. Pesquisa Veterinária Brasileira 24(3):132-143. Depto Clínicas Veterinárias, Universidade Federal de Campina Grande, Patos, PB 58700-000, Brazil. E-mail: verônica.nobre@uol.com.br

From 2000 to 2003 eight cases of poisoning by Crotalaria retusa L. were observed in horses on 8 farms in the semiarid region of Paraíba and Ceará. C. retusa was found in all farms. The main clinical signs were characteristic of hepatic encephalopathy, with dullness or hyperexcitability, head pressing, compulsive walking or circling and, occasionally, violent uncontrollable galloping. Decreased cranial nerve reflexes, ataxia and weakness were also observed. Other clinical signs were anorexia, weight loss, photosensitization and jaundice. The clinical manifestation period varied from 4 to 40 days, but most horses had a previous history of weight loss. At necropsy the livers were hard, with irregular surface and white areas mixed with dark red areas and increased lobular pattern. Mild jaundice, ascitis, hydropericardium and hydrothorax were also observed. Edema and moderate congestion were seen in the lungs. Histologic changes of the liver were characterized by fibrosis, mainly periportal, megalocitosis and bile duct cell proliferation. Multifocal areas of centrilobular or midzonal hemorrhages were also observed. Centrilobular hemorrhagic necrosis was present in two horses. Alzheimer type II astrocytes were observed, isolated or in groups, mainly in the caudate nucleus and cortex in 4 horses. The poisoning was experimentally produced in 1 adult horse and 3 adult donkeys. The horse received daily $100 \mathrm{~g}$ of $\mathrm{C}$. retusa seeds and died 52 days after the beginning of the experiment. The dried whole $\mathrm{C}$. retusa was mixed with grass and given to the 3 experimental donkeys at daily doses of $10 \mathrm{~g} / \mathrm{kg}, 5 \mathrm{~g} / \mathrm{kg}$ and $2.5 \mathrm{~g} / \mathrm{kg}$, respectively. The donkey treated with $5 \mathrm{~g}$ per $\mathrm{kg}$ died 48 days after beginning of the experiment and the other two were sacrificed at 120 days. Clinical signs and pathology were similar to those observed in spontaneous cases, but Alhzeimer type II astrocytes were observed only in the donkey that died 48 days after the beginning of ingestion of the plant material. The concentration of monocrotaline in the whole plant given to the donkeys was $0.5 \%$
\end{abstract}

INDEX TERMS: Poisonous plants, plant poisoning, Crotalaria retusa, Fabaceae, hepatic cirrhosis, horse, pirrolizidine alkaloids.

\footnotetext{
${ }^{1}$ Recebido em 12 de abril de 2004.

Aceito para publicação em 23 de abril de 2004.

Trabalho financiado pelo Programa de Apoio a Núcleos de Excelência (PRONEX),. Proc.CNPq no.767102600.

${ }^{2}$ Centro de Saúde e Tecnologia Rural, Universidade Federal de Campina Grande, 58700-000 Patos, PB.

3 Depto Ciências Farmacêuticas, Universidade Federal da Paraíba, ITF, 58057 970 João Pessoa, PB.
}

RESUMO.- De 2000 a 2003 oito casos de intoxicação por Crotalaria retusa $L$. foram observados em eqüinos em 8 fazendas na região semi-árida da Paraíba e do Ceará. C. retusa foi encontrada no pasto em todas as propriedades. Os principais sinais clínicos foram característicos de encefalopatia hepática, com apatia ou hiperexcitabilidade, pressão da cabeça, andar compulsivo ou em círculo e, ocasionalmente, galope descontrolado e violento. Decréscimo nos reflexos dos 
nervos craniais, ataxia e fraqueza foram também observados. Outros sinais clínicos foram anorexia, perda de peso, fotossensibilização e icterícia. 0 curso clínico variou de 4 a 40 dias, mas muitos cavalos tinham um histórico prévio de perda de peso. À necropsia os fígados eram duros, com superfície irregular e áreas brancas misturadas com áreas vermelho-escuras e com aumento no padrão lobular. Icterícia moderada, ascite, hidropericárdio e hidrotorax foram também observados. Edema e moderada congestão foram observadas nos pulmões. As lesões histológicas do fígado foram caracterizadas por fibrose, principalmente periportal, megalocitose e proliferação de células dos ductos biliares. Áreas multifocais de hemorragias centrolobulares ou mediozonais foram também observadas. Necrose hemorrágica centrolobular estava presente em dois eqüinos. Foram observados astrócitos Alzheimer tipo II, isolados ou em grupos principalmente no núcleo caudato e córtex em 4 eqüinos. $A$ intoxicação foi produzida experimentalmente em 1 eqüino e 3 asininos. 0 eqüino adulto, recebeu diariamente, $100 \mathrm{~g}$ de sementes de $\mathrm{C}$. retusa e morreu aos 52 dias após o início do experimento. $C$. retusa inteira, seca foi misturada com capim e dada a 3 asininos adultos em doses diárias de $10 \mathrm{~g} / \mathrm{kg}, 5 \mathrm{~g} /$ $\mathrm{kg}$ e $2,5 \mathrm{~g} / \mathrm{kg}$ respectivamente. 0 asinino tratado com $5 \mathrm{~g} / \mathrm{kg}$ morreu aos 48 dias após o início do experimento e os outros dois foram sacrificados aos 120 dias. Os sinais clínicos e a patologia foram similares aos observados nos casos espontâneos, alguns astrócitos Alzheimer tipo II foram observados somente no asinino que morreu após 48 dias do inicio da ingestão. A concentração de monocrotalina na planta inteira administrada aos asininos foi $0,5 \%$

TERMOS DE INDEXAÇÃO: Plantas tóxicas, intoxicação por plantas, Crotalaria retusa, Fabaceae, cirrose hepática, cirrose hepática, encefalopatia hepática, eqüinos, alcalóides pirrolizidínicos.

\section{INTRODUÇÃO}

Mais de 600 espécies do gênero Crotalaria são encontradas em diversas regiões do mundo, sendo a maioria tóxica para animais (Williams \& Molyneux 1987). As variedades tóxicas mais conhecidas são Crotalaria spectabilis, Crotalaria crispata, Crotalaria retusa, Crotalaria dura e Crotalaria globifera (Barri \& Adam 1981). Em diversos países foram descritos casos de intoxicação por Crotalaria, contendo alcalóides pirrolizidínicos (AP), em eqüinos (Gibbons et al. 1953, Gardiner et al. 1965, Arzt \& Mount 1999, Pitt \& Mckenzie 2002), bovinos (Barri \& Adam 1981, Winter et al. 1990), suínos (Peckham et al. 1974, McGrath \& Duncan 1975), aves (Norton \& O'Rourke 1979, Alfonso et al., 1993) e caprinos (Barri \& Adam 1984). C. retusa e C. crispata são responsáveis pela doença denominada Kimberley horse disease ou Walkabout disease na Austrália (Rose et al. 1957a,b, Gardiner et al. 1965).

Na década de 1990 foram descritos casos de intoxicação espontânea por Crotalaria spp em diferentes estados brasileiros. No Estado de Minas Gerais foi descrito um surto de intoxicação em eqüinos por C. juncea (Nobre et al. 1994). Em bovinos foi descrita a intoxicação por Crotalaria spp. no Mato Grosso do Sul e em Minas Gerais (Lemos \& Barros 1998). Na
Paraíba, foram documentados casos de intoxicação por C. retusa em ovinos (Dantas et al. 1999), eqüídeos e bovinos (Nobre et al. 2004). Intoxicação por AP também tem sido reproduzida experimentalmente no Brasil em bovinos com C. anagiroides (Tokarnia \& Döbereiner 1983), em ratos e cabras com C. spectabilis (Medeiros et al. 1994) e em suínos com C. spectabilis (Souza et al. 1997, Torres et al. 1997).

Eqüinos intoxicados por Crotalaria retusa apresentam um quadro clínico de anorexia, atordoamento, mal estado geral, irritabilidade, bocejos, espasmos musculares, incordenação, cabeça baixa, agressividade, andar a esmo e galope sem rumo (Gardiner et al. 1965, Nobre et al. 2004). Sintomatologia semelhante foi relatada na intoxicação de eqüinos por outras espécies de Crotalaria (Arzt \& Mount 1999, Pitt \& Mckenzie 2002). Os achados de necropsia são característicos de uma doença hepática crônica. 0 fígado encontra-se firme, aumentado de volume (Gibbons 1953, Gardiner et al. 1965, Nobre et al. 1994, Arzt \& Mount 1999) e com aspecto mosqueado (Arzt \& Mount 1999). Nos pulmões as principais alterações observadas são edema e congestão pulmonar com áreas consolidadas no parênquima (Gardiner et al. 1965, Nobre et al. 1994). Histologicamente as principais alterações são observadas no fígado e incluem fibrose, hepatomegalocitose (Gibbons et al. 1953, Gardiner et al. 1965, Arzt \& Mount 1999), necrose (Gardiner et al. 1965), vacuolização de hepatócitos (Nobre et al. 1994), hemorragia (Arzt \& Mount 1999), e em alguns casos, proliferação de ductos biliares (Gardiner et al. 1965, Arzt \& Mount 1999). Os pulmões podem apresentar alveolite fibrosante difusa, com espessamento de septos interalveolares, edema e infiltrado inflamatório mononuclear e, principalmente, macrófagos espumosos (Gardiner et al. 1965, Nobre et al. 1994). Eqüinos submetidos a estresse metabólico ou nutricional na seca, carga de trabalho pesada ou gravidez, são mais prováveis de serem afetados pela doença (urra net al. 1996). A doença crônica é a forma usual da intoxicação e os sinais clínicos ocorrem semanas a meses após a planta ter sido ingerida. Os danos hepáticos são progressivos e a morte pode ocorrer meses ou até mesmo anos após a ingestão de plantas contendo AP (Cheeke 1998).

Este trabalho tem como objetivo descrever os casos de intoxicação por $C$. retusa em eqüinos no semi-árido, no período de 2000 a 2003, complementando um trabalho anterior no qual foram descritos surtos de intoxicação por $C$. retusa na mesma região (Nobre et al. 2004). É descrita também a reprodução experimental da intoxicação em três asininos e um eqüino. Dados iniciais sobre a reprodução experimental foram publicados anteriormente (Nobre et al. 2004).

\section{MATERIAL E MÉTODOS}

\section{Intoxicação espontânea em eqüinos}

Os dados referentes à epidemiologia e sinais clínicos foram colhidos junto aos proprietários dos animais e Médicos Veterinários e observados em visitas as propriedades afetadas com o problema. Os casos ocorreram em oito propriedades no período de 2000 a 2003. Sete animais foram necropsiados. Fragmentos de tecidos, incluindo fígado, intestinos, rins, baço, pulmões, coração e encéfalo foram fixados em formol a $10 \%$ processados rotineiramente para 
estudo histológico e corados pela coloração de hematoxilina e eosina (HE). $O$ fígado e pulmão foram corados também pelo Tricrômico de Masson. No encéfalo foram clivados fragmentos do córtex frontal, occipital, parietal e temporal; núcleos da base e cápsula interna; tálamo e hipotálamo, colículo rostral, cerebelo, ponte e medula oblonga. Em 4 animais foram processados, também, cortes transversais e longitudinais da medula cervical, torácica e lombar. 0 Eqüino 2 foi necropsiado pelo veterinário atuante, sendo encaminhado apenas o fígado ao Laboratório de Patologia Animal.

Como controle positivo para as lesões histológicas de encefalopatia hepática foi utilizada uma lâmina cedida pelo Dr. Brian Summers (College of Veterinary Medicine, Cornell University) de fragmento do núcleo da base com numerosos astrócitos Alzheimer tipo II, oriunda de um cavalo com encefalopatia hepática de causa desconhecida. 0 animal apresentava como sinais clínicos depressão, ataxia, pressão da cabeça em objetos e andava em círculo. No exame histológico do fígado verificou-se fibrose e necrose hepatocelular. Foram utilizados ainda, como controle negativo, encéfalos de dois cavalos sacrificados no Laboratório de Patologia Animal, com fraturas de membros. Fragmentos do encéfalo foram clivados nas mesmas regiões e seqüência dos que foram encaminhados nos animais com intoxicação espontânea por $\mathrm{C}$. retusa. Desses mesmos animais colheuse também fragmentos do pulmão e fígado para controle das lesões hepáticas e pulmonares.

Em três eqüinos foram realizados exames sangüíneos para determinação das enzimas aspartato aminotransferase (AST), ãglutamiltransferase (GGT), creatinina quinase (CPK) e fosfatase alcalina (FA).

\section{Coleta da planta}

Foram colhidas amostras da planta para identificação botânica da espécie existente na região e para análise fitoquímica no Laboratório de Tecnologia Farmacêutica da UFPB. Para análise fitoquímica foi utilizada a planta inteira seca a sombra, moída, macerada com etanol a $95 \%$ concentrada em aparelho de rotavapor e em seguida procedida à extração dos alcalóides e identificação dos constituintes por análise espectrofométrica (Barbosa Filho et al. 1997).

\section{Intoxicação experimental em eqüinos e asininos}

Para reproduzir a intoxicação por Crotalaria retusa em eqüídeos utilizaram-se um eqüino macho adulto sem raça definida e quatro asininos adultos de ambos os sexos da raça Jumento Nordestino, os quais foram pesad os e alojados em baias individuais com comedouros e bebedouros. Foram realizados exames clínicos usuais, vermifugação e vacinação anti-rábica. Os animais recebiam diariamente alimentação a base de capim-elefante picado e farelo de milho ou trigo. Antes da administração de capim o eqüino recebeu diariamente durante 52 dias, $100 \mathrm{~g}(0,4 \mathrm{~g} / \mathrm{kg})$ de sementes de C. retusa moídas em moinho de cereais e misturadas a $1 \mathrm{~kg}$ de farelo de milho. Os asininos receberam durante 30, 90 e 120 dias, $10 \mathrm{~g} / \mathrm{kg}, 5 \mathrm{~g} / \mathrm{kg}$ e 2,5 g/kg, respectivamente, das partes aéreas de $\mathrm{C}$. retusa no estágio adulto, seca a sombra e moída, misturada a $1 \mathrm{~kg}$ de capim-elefante picado ou farelo de milho. Um quarto asinino não recebeu a planta e serviu como controle.

Aos 52 dias o eqüino morreu e foi necropsiado. 0 asinino que ingeriu $5 \mathrm{~g} / \mathrm{kg}$, morreu aos 48 dias e os asininos que ingeriram $10 \mathrm{~g} / \mathrm{kg}$ e 2,5 g/kg, foram sacrificados aos 120 dias e necropsiados. Coletaram-se fragmentos de fígado, rim, pulmão, coração e encéfalo, os quais foram incluídos em parafina, cortados em secções de $5 \mu$ e corados pela hematoxilina e eosina (HE) para estudo histológico das lesões. Os cortes do encéfalo foram feitos nas mesmas regiões que as dos casos espontâneos.

\section{RESULTADOS}

\section{Intoxicação espontânea}

Epidemiologia e sinais clínicos. Os dados de cada caso de intoxicação por Crotalaria. retusa estão no Quadro1. Foram observados oito casos de intoxicação por C. retusa, sendo sete verificados na Paraíba e um no Ceará. Os Eqüinos 1, $4,5,6,7$ e 8 eram soltos no pasto nativo e suplementados com capim elefante e ração comercial de fonte indeterminada. Os Eqüinos 2 e 3 estavam soltos no pasto e não recebiam suplementação.

Em seis eqüinos a doença teve evolução variável entre 4 e 15 dias. No Eqüino 1 a doença evoluiu em 20 dias e no Eqüino 8, evoluiu em 40 dias. Apenas um animal adoeceu em cada propriedade. $\mathrm{Na}$ propriedade $\mathrm{C}$, em anos anteriores tinha ocorrido a morte de dois eqüinos, com sintomatologia semeIhante. Em todas as propriedades havia C. retusa no pasto (Fig.1).

Os principais sinais clínicos eram cerebrais, caracterizados por depressão (Fig.2) alteração do comportamento, movimentos involuntários, pressão da cabeça contra objetos (Fig.3), andar a esmo ou em círculos e galope desenfreado com batidas em cercas ou outros obstáculos. Alguns animais apresentavam ainda sinais de comprometimento do tronco encefálico, caracterizados por ataxia, com permanência de membros anteriores e posteriores em abdução (Fig.4) ou cruzados, batidas da parte anterior dos membros em objetos ao serem forçados a ultrapassá-los e arrastar das pinças durante a marcha. Apresentavam também alterações dos núcleos dos nervos cranianos caracterizadas por facilidade para extrair forçadamente a língua e permanência da mesma parcialmente fora da cavidade oral (Fig.5), reflexo pupilar dimi-

Quadro 1. Dados epidemiológicos em 8 surtos de intoxicação por Crotalaria retusa em eqüinos

\begin{tabular}{|c|c|c|c|c|c|c|c|}
\hline $\begin{array}{c}\text { Eqüino/Pro- } \\
\text { priedade }\end{array}$ & $\begin{array}{l}\text { № de } \\
\text { eqüinos }\end{array}$ & $\begin{array}{l}\text { Idade } \\
\text { (anos) }\end{array}$ & Sexo & Raça & $\begin{array}{c}\text { Mês da } \\
\text { morte/ ano }\end{array}$ & $\begin{array}{l}\text { Evolução } \\
\text { da doença }\end{array}$ & $\begin{array}{l}\text { Local de } \\
\text { ocorrência }\end{array}$ \\
\hline $1-\mathrm{A}$ & 5 & 3 & $\mathrm{~F}$ & SRD & Jan. 2000 & 20 dias & Patos, \\
\hline $2-B$ & 31 & 12 & M & Puro Sangue Inglês & Mai. 2001 & 15 dias & São José Bonfim, PB \\
\hline $3-C$ & 6 & 1 & M & Mestiço Quarto de Milha & Abr. 2002 & 15 dias & Patos, PB \\
\hline $4-D$ & 4 & 9 & $\mathrm{~F}$ & Mestiço Appaloosa & Mai. 2002 & 4 dias & São José Bonfim, PB \\
\hline $5-E$ & 5 & 2 & M & Puro Sangue Inglês & Out. 2002 & 5 dias & Patos, PB \\
\hline $6-F$ & 20 & Adulto & M & SRD & Out. 2002 & 15 dias & Santa Terezinha, PB \\
\hline $7-G$ & 7 & 12 & $\mathrm{~F}$ & Quarto de Milha & Out. 2002 & 10 dias & Patos, PB \\
\hline $8-\mathrm{H}$ & 6 & Adulto & M & Quarto de Milha & Out. 2003 & 40 dias & Mauriti, CE \\
\hline
\end{tabular}



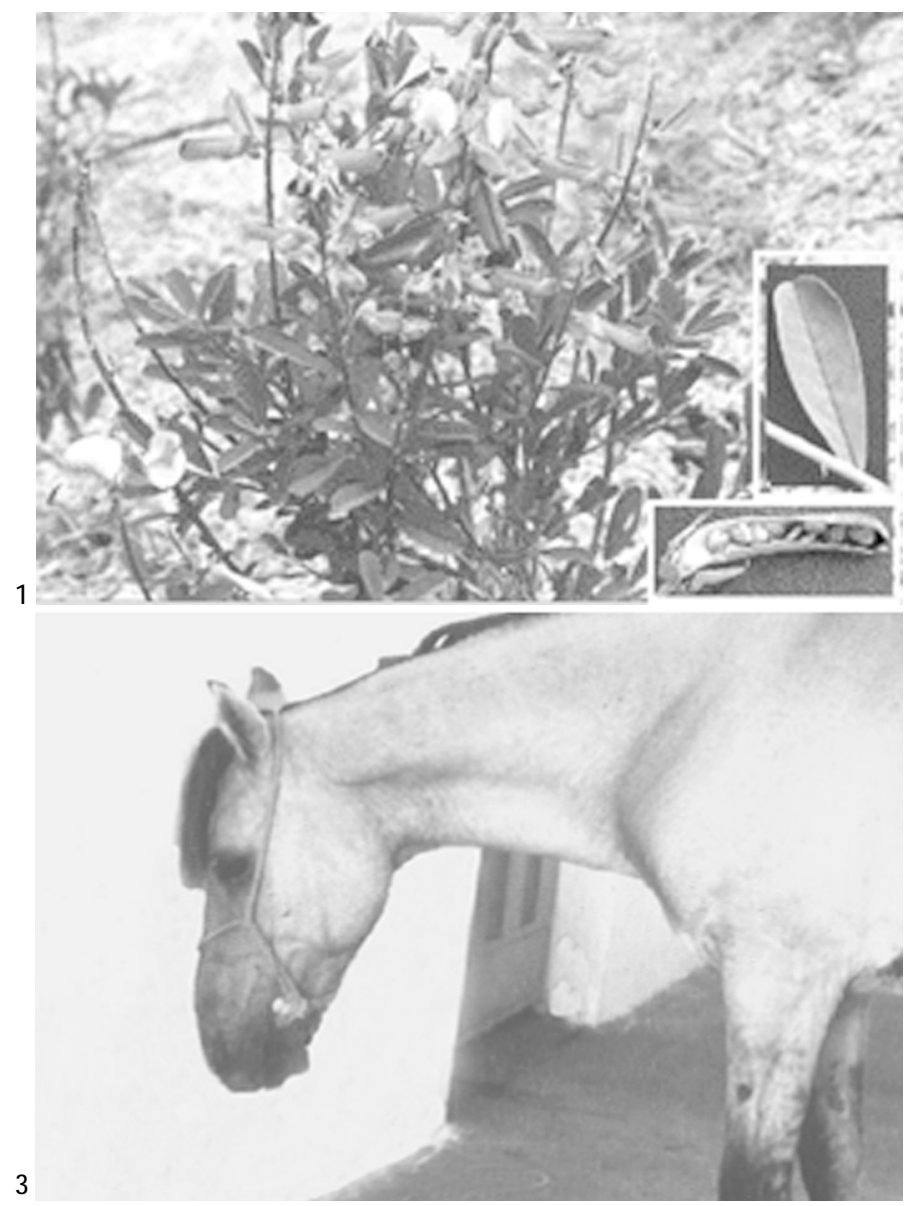

Fig.1. Crotalaria retusa, município de Patos, Paraíba. No detalhe a vagem com sementes reniformes e a folha mostrando formato característico, com emarginação do ápice (retuso), detalhe que confere nome a espécie.

Fig.3. Eqüino 7 mostrando pressão da cabeça contra a parede, na intoxicação por C. retusa.

nuído e dificuldade de deglutição. Eqüino 8 apresentou debilidade dos membros posteriores e anteriores durante a marcha. Eqüino 4 apresentou lesões de fotossensibilização na face. No Eqüino 5 observou-se secreção catarral pelas narinas e no Eqüno 7 aborto. Em todos os casos havia história de anorexia e emagrecimento.

Os testes bioquímicos do soro sangüíneo revelaram aumento da AST e CPK no Eqüino 4 e aumento da AST, GGT e fosfatase alcalina nos Eqüinos 5 e 8.

Classificação e análise fitoquímica da planta. A planta foi classificada como Crotalaria retusa L. Um exemplar foi depositado no Herbário Lauro Pires Xavier do Laboratório de Tecnologia Farmacêutica da Universidade Federal da Paraíba identificada como Agra \& Góis 3607 (JPB). A análise fitoquímica de $4.500 \mathrm{~kg}$ das partes aéreas da planta revelou como principal alcalóide pirrolizidínico a monocrotalina, numa concentração de 0.5\%(Azevedo Junior et al. 2000).

Achados de necropsia. Todos os animais apresentaram mal estado geral e Eqüino 5 exibia escoriações em diversas

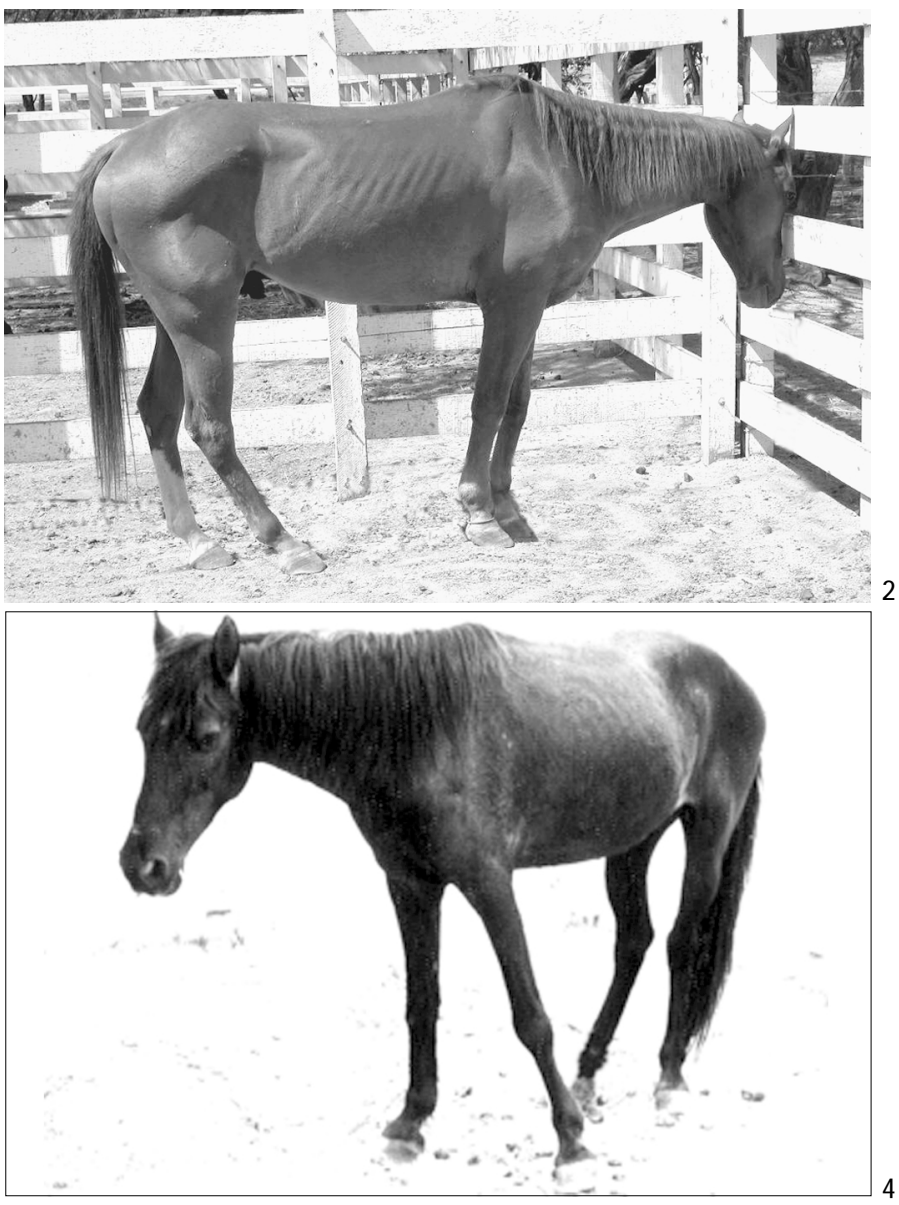

Fig.2. Eqüino 8 mostrando marcada depressão e encostando a cabeça na cerca, na intoxicação por C. retusa.

Fig.4. Eqüino 3 mostrando ataxia caracterizada por abdução dos membros anteriores, na intoxicação por C. retusa.

regiões do corpo, principalmente nos membros. A maioria dos animais apresentou líquido na cavidade abdominal. Eqüino 5 apresentou hidropericárdio. Os Eqüinos 5 e 6 apresentaram hemorragias no epicárdio e miocárdio.

A lesão mais proeminente em todos os animais foi verificada no fígado que tinha consistência aumentada, com cápsula levemente esbranquiçada, superfície irregular e alternância de áreas amareladas ou pálidas entremeadas com áreas vermelho-escuras, sem uniformidade (Fig. 6). Eqüino 5 apresentou pontos esbranquiçados na superfície capsular. Os Eqüinos 5 e 6 exibiram áreas avermelhadas no fígado. Os pulmões da maioria dos animais apresentam-se edematosos e congestos. Eqüino 4 apresentou áreas multifocais de 1-2 $\mathrm{mm}$ distribuídas por todo o órgão e abscessos com pus consistente formando aparentemente camadas, concêntricas semelhante à cebola. Os Eqüinos 5 e 6 apresentaram equimoses na superfície pulmonar. Os rins da maioria dos eqüinos eram levemente congestos. 0 rim do Eqüino 5 exibiu edema na cápsula. Alguns animais exibiam discreta icterícia. Não fo- 
Quadro 2. Principais aspectos histopatológicos do fígado de eqüinos intoxicados espontaneamente por Crotalaria retusa, com referência à gravidade da lesão ${ }^{a}$

\begin{tabular}{cccccccccc}
\hline Eqüino & \multicolumn{2}{c}{ Fibrose } & Megalo- & Proliferação & \multicolumn{2}{c}{ Necrose } & \multicolumn{2}{c}{ Vacuolização } & Hemorragia \\
\cline { 2 - 3 } (Ficha) & Periportal & Intralobular & citose & ductal & Centrolobular & Individual & de hepatócitos \\
\hline
\end{tabular}

${ }^{\mathrm{a}}+++$ acentuada,++ moderada,+ discreta, - ausente.

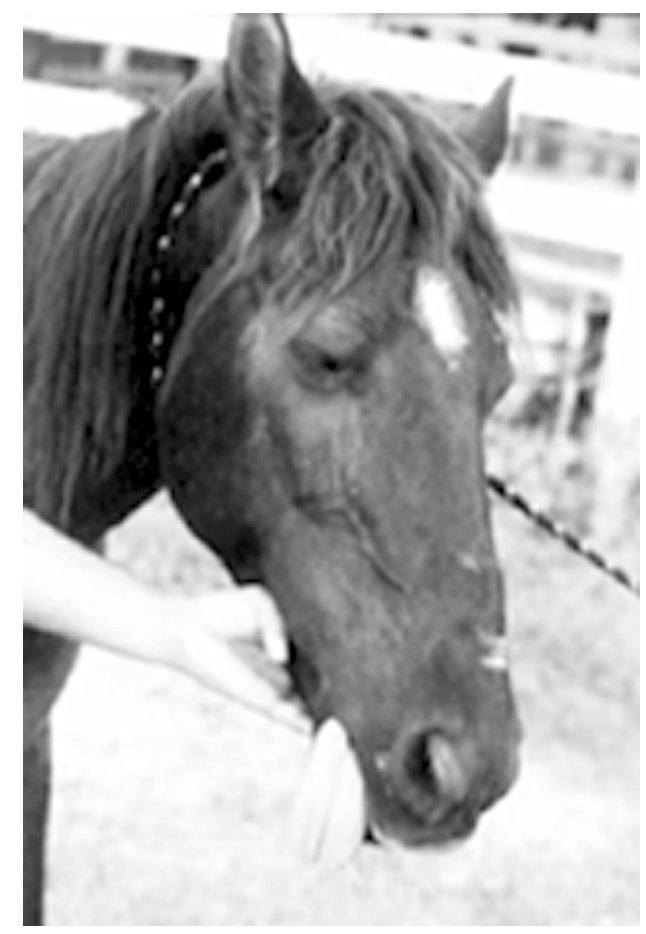

Fig.5. Eqüino 3 mostrando protusão da língua causada por lesões na medula oblonga (núcleo do XII par craniano), na intoxicação por C. retusa.

ram observadas alterações macroscópicas significativas nos demais órgãos.

Achados histológicos. A principal alteração histológica foi verificada no fígado (Quadro 2). A maioria dos cortes, caracterizou-se por variáveis graus de fibrose, predominantemente periportal, às vezes com infiltrado inflamatório, principalmente mononuclear. Havia proliferação de células dos ductos biliares no espaço porta e em al guns casos intralobular. Megalocitose estava presente no fígado de todos os animais, sendo caracterizada pelo aumento do citoplasma e do núcleo, que tinha a cromatina nuclear distribuída irregularmente. (Fig. 7)

Os Eqüinos 5 e 6 apresentavam necrose hemorrágica preferencialmente centrolobular, associada à congestão e hemorragias, que coaleciam com áreas vizinhas em alguns cor- tes. Ainda pode-se observar vacuolização de hepatócitos, principalmente centrolobulares, nos Eqüinos 1, 2, 5, 6 e 7 e nódulos regenerativos no Eqüino 3 (Fig. 8). Nos rins observouse marcada congestão com hemorragias preferencialmente na medular, sendo mais acentuadas nos Eqüinos 5, 6 e 8. Havia discreta vacuolização do epitélio tubular nos Eqüinos 1, 3, 7 e 8. No Eqüino 7 observaram-se também, cilindros hialinos. Os Eqüinos 1, 7 e 8 apresentavam algumas células tubulares aumentadas de tamanho, sugerindo megalocitose.

Nos pulmões a principal alteração foi congestão e edema, sendo marcada no Eqüino 1. Observou-se, ainda, discreto espessamento de septos interalveolares nos Eqüinos 3 e 5. Os Eqüinos 3, 5 e 6 apresentaram discreto espessamento da parede das arteríolas. As lesões foram melhor visualizadas nos cortes corados pela técnica de Tricomico de Masson. Eqüino 1 exibiu infiltrado inflamatório principalmente mononuclear, mais acentuado na região perivascular. Nos Eqüinos 3 e 8 observaram-se algumas células endoteliais tumefeitas. Eqüino 4 apresentou pneumonia multifocal granulomatosa difusa, sugestiva de infecção por Rhodococus equi.

Em todos os cortes do encéfalo, com exceção do eqüino 2 , havia congestão e discretas hemorragias, principalmente perivasculares. Os Eqüinos 1, 5, 6, 7 e 8 exibiram astrócitos aumentados, com núcleos vesiculares e arranjados aos pares ou múltiplos (Fig. 9) sendo mais evidenciados no núcleo caudato e nos fragmentos do córtex. Estas células são denominadas de astrócitos Alzheimer tipo II (Summers et al. 1995).

\section{Intoxicação experimental em eqüinos e asininos}

Sinais clínicos. 0 eqüino alimentado com farelo de miIho contendo $100 \mathrm{~g}$ de semente de $C$. retusa apresentou, após 15 dias de administração, anorexia progressiva, corrimento nasal bilateral, depressão e incoordenação. Aos 51 dias de experimento 0 animal apresentava-se agitado, andando em círculos, com incoordenação, arrastando as pinças, e deitando e levantando-se rapidamente. Posteriormente permaneceu em decúbito lateral até a morte, aproximadamente 24 horas após.

0 asinino que ingeriu a dose de $5 \mathrm{~g} / \mathrm{kg}$ morreu aos 48 dias de experimento e os demais ingeriram a planta durante 120 dias e foram sacrificados. Todos os animais experimentais 


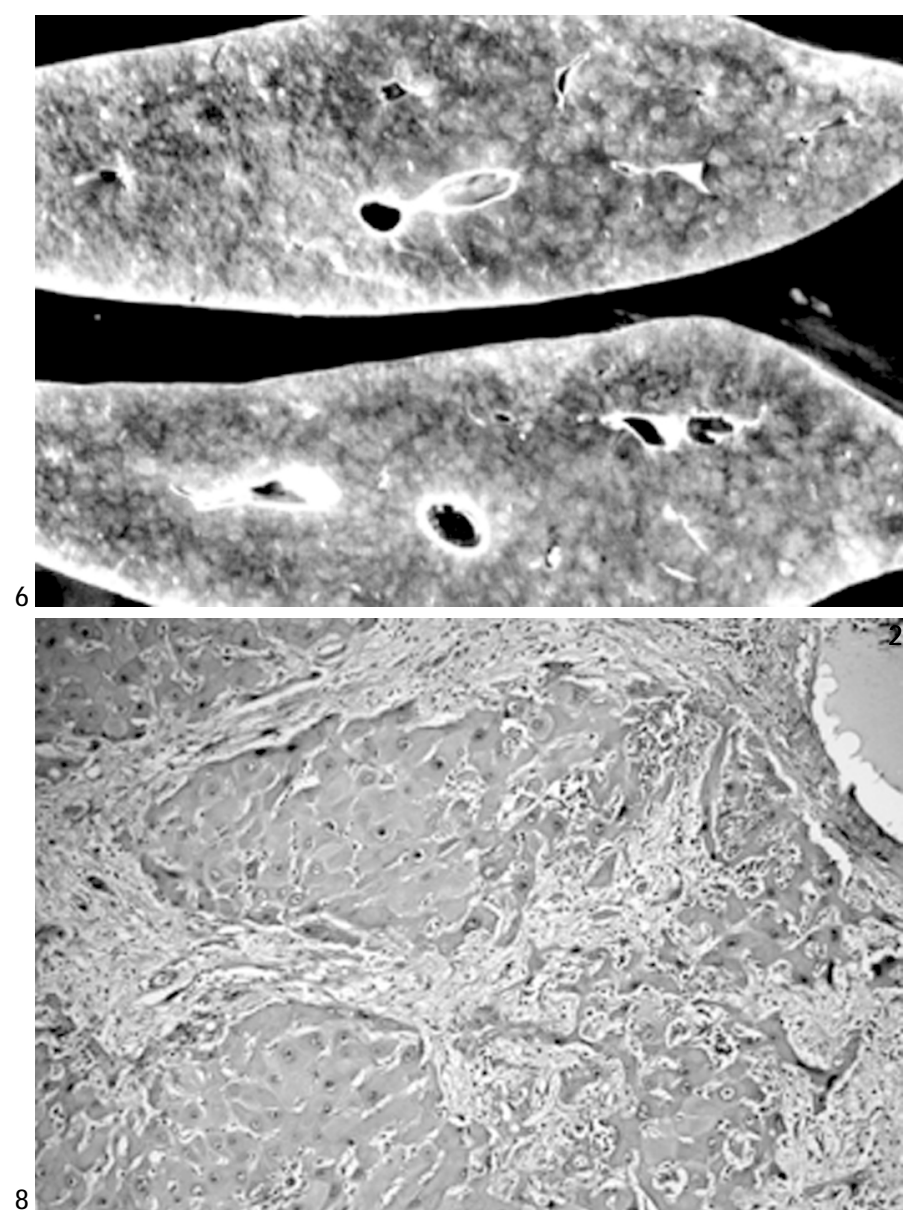

Fig.6. Fígado com superfície de corte irregular mostrando alternância de áreas claras esbranquiçadas com áreas vermelho escuras, sem uniformidade, na intoxicação espontânea por Crotalaria retusa. (Equino 7)

Fig.8. Fibrose e nódulos regenerativos no fígado, na intoxicação espontânea por C. retusa. HE, obj. 20. (Eqüino 3)

apresentaram anorexia, depressão, cabeça baixa e discreta icterícia. 0 animal que morreu aos 48 dias de experimento apresentou 24 horas antes da morte, sinais nervosos, incluindo incoordenação e tremores musculares; durante a marcha arrastava as pinças e antes de morrer jogou-se contra a cerca.

0 asinino que não foi alimentado com a planta e serviu como controle não apresentou nenhuma alteração clínica.

Achados de Necropsia. Os animais experimentais exibiram perda da condição corporal e mau estado nutricional. 0 eqüino apresentava aproximadamente 5 litros de líquido levemente amarelado e límpido na cavidade abdominal. 0 fígado encontrava-se duro com áreas vermelho- escuras alternadas com áreas esbranquiçadas. Os pulmões eram vermelhos escuros com discreta quantidade de espuma na traquéia e brônquios. Os rins estavam levemente congestos, principalmente na junção cortiço-medular. Nos intestinos, principalmente no delgado, o conteúdo estava mais fluido que o normal.

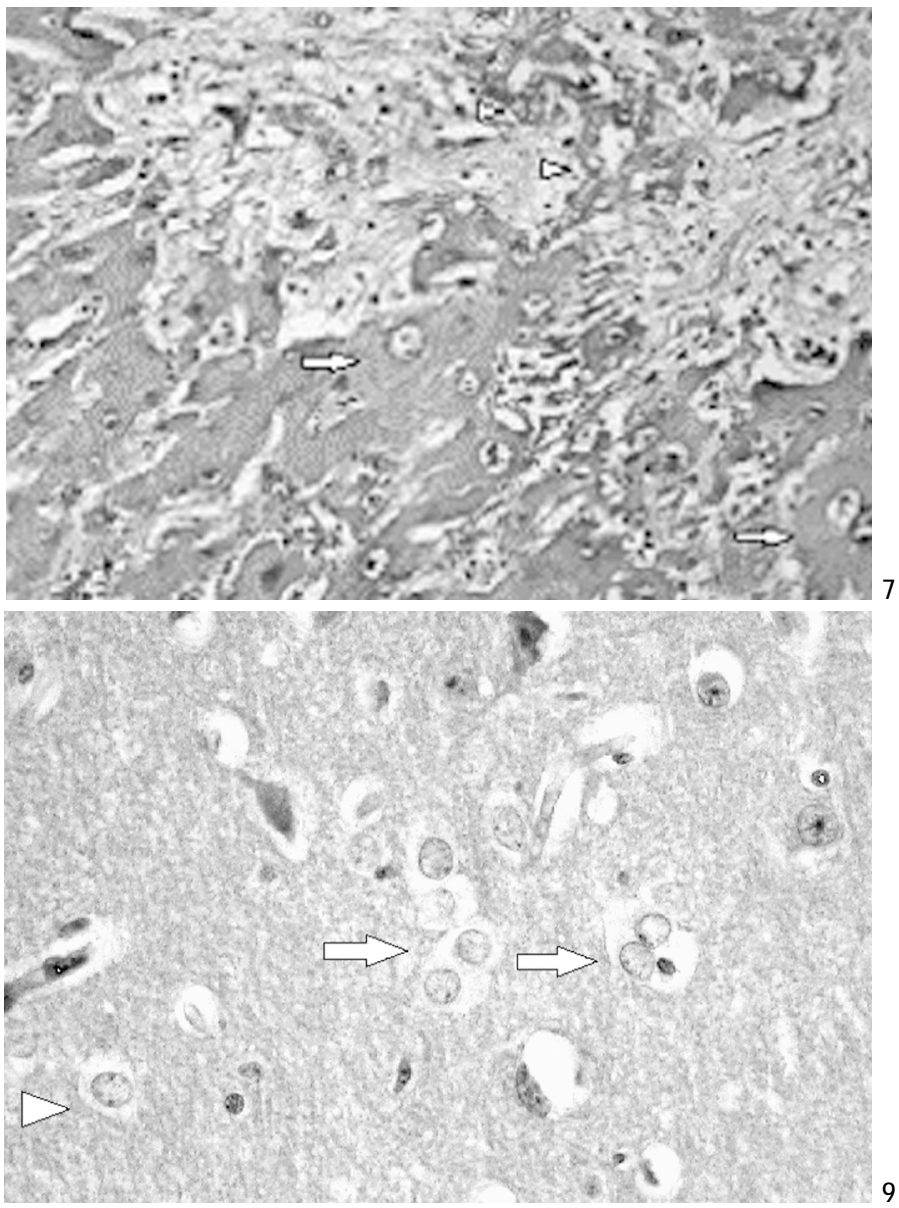

Fig.7. Fibrose hepáticapreferencialmente periportal, megalocitose (seta) e discreta proliferação de células epiteliais dos ductos biliares (cabeça de seta). HE, obj. 20. (Eqüino 3)

Fig.9. Astrócitos Alzheimer tipo II, caracterizados por núcleos aumentados de volume e com aspecto vesicular, agrupados (setas) ou isolados (cabeça de seta), no encéfalo (Núcleo caudato), na intoxicação espontânea por C. retusa. HE, obj. 40. (Eqüino 8)

Os asininos que foram sacrificados aos 120 dias apresentaram líquido na cavidade abdominal. Os fígados de todos os animais experimentais tinham a cápsula esbranquiçada com áreas amareladas alternadas com áreas vermelhas escuras e tinham consistência aumentada. Os pulmões de todos os animais exibiam discreto edema e congestão e os rins eram levemente pálidos.

Achados histológicos. As principais alterações microscópicas foram observadas no fígado. No cavalo, o fígado apresentou severa desorganização do parênquima, megalocitose, severa vacuolização de hepatócitos e discreta fibrose periportal. Nas áreas centrolobulares se verificava perda de hepatócitos e substituição por tecido conjuntivo jovem. Os pulmões apresentavam discreto edema e congestão. Nos rins observou-se discreta vacuolização multifocal de células tubulares e discreta congestão.

Os asininos que ingeriram Crotalaria retusa na doses de 10 $\mathrm{g} / \mathrm{kg}$ e $2,5 \mathrm{~g} / \mathrm{kg}$ apresentaram no fígado, discreta fibrose 
periportal com infiltração de células mononucleares indiferenciadas no tecido fibroso. Os hepatócitos, principalmente das áreas centrolobulares, exibiam severa vacuolização microvesicular, sendo que alguns hepatócitos apresentavam vacúolos maiores. Havia, também, hepatócitos necróticos, hepatócitos com retenção de bile e outros com megalocitose. Algumas áreas centrolobulares exibiam hemorragias, principalmente no animal que ingeriu $10 \mathrm{~g} / \mathrm{kg}$ diariamente. Verificou-se ainda hemossiderose . 0 animal que morreu aos 48 dias exibiu fibrose discreta, preferencialmente periportal, megalocitose, desorganização do parênquima hepático, com hepatócitos necróticos e severa vacuolização de hepatócitos, preferencialmente nas áreas centrolobulares. Observou-se também congestão difusa e hemorragias principalmente centrolobulares, além de severa retenção biliar e proliferação de células de ductos biliares.

0 asinino que ingeriu $10 \mathrm{~g} / \mathrm{kg}$ de $\mathrm{C}$. retusa diariamente apresentou áreas de pneumonia intersticial com engrossamento do septo que exibia células mononucleares e discreta quantidade de tecido conjuntivo. Havia maior acúmulo de tecido conjuntivo localizado perivascularmente. 0 animal que ingeriu $5 \mathrm{~g} / \mathrm{kg}$ exibiu áreas de pneumonia intersticial com infiltração de células mononucleares e tecido conjuntivo, hiperplasia do epitélio bronquiolar e congestão severa. 0 animal que ingeriu $2,5 \mathrm{~g} / \mathrm{kg}$ não apresentou lesões significativas nos pulmões.

Nos rins do animal que ingeriu $5 \mathrm{~g} / \mathrm{kg}$ da planta observouse marcada congestão e nefrose discreta. Em alguns túbulos as células epiteliais apresentam-se vacuolizadas, enquanto que em outros estavam necróticas. Havia a presença de alguns cilindros hialinos. Os asininos que ingeriram doses de $10 \mathrm{~g} /$ $\mathrm{kg}$ e 2,5 g/kg diariamente não apresentaram lesões significativas nos rins.

Nos cortes do encéfalo do asinino com morte natural aos 48 dias verificaram-se discretos grupos de astrócitos Alzheimer tipo II, sendo bem evidenciados no núcleo caudato. Os outros dois asininos não apresentaram alterações no cérebro.

\section{DISCUSSÃO E CONCLUSÕES}

0 diagnóstico de intoxicação por Crotalaria. retusa, foi baseado nos sinais clínicos e lesões características, pela presença da planta nas propriedades onde ocorreram os casos e pela reprodução da doença em 1 eqüino e em 3 asininos. Casos semelhantes vêm sendo observados há 10 anos no semi-árido da Paraíba e regiões circunvizinhas. De 1996 a 1999 ocorreram 15 casos da doença (Nobre et al. 2004) e neste trabaIho são descritos mais 8 casos.

$\mathrm{Na}$ região semi-árida as estações do ano não são bem estabelecidas, percebendo-se apenas duas estações, a das chuvas (janeiro a junho) e a da estiagem (julho a dezembro). 0 período de chuvas é bastante irregular e em alguns anos quase não chove nesta região. No primeiro período do ano $\mathrm{C}$. retusa brota em áreas de baixio, próximo a açudes e rios temporários. Nos primeiros meses da estação seca é vista na fase adulta, em sementação, sendo abundante nas áreas referi- das, muitas vezes se constituindo na única planta verde. Nos meses de novembro e dezembro ocorre escassez da planta, sendo que nas áreas irrigadas e próximas a açúdes ela ainda está presente, em diversos estágios de crescimento (brotação, floração e sementação). No período mais seco do ano, com o pasto seco, os animais tendem a procurar as áreas ribeirinhas de açudes e áreas irrigadas a procura de pasto verde, podendo ingerir Crotalaria. Apesar das diferenças na distribuição das chuvas e, portanto, da disponibilidade de forragem nas duas épocas do ano, não foi constatada distribuição sazonal da enfermidade. Nos oito eqüinos estudados neste trabalho, quatro casos ocorreram no primeiro perío do do ano, chuvoso, e quatro casos no período de estiagem. Também não foi observada distribuição sazonal nos casos que ocorreram de 1996 a 1999, ocorrendo 9 casos no primeiro período do ano e 6 casos no período seco (Nobre et al. 2004). A ocorrência da doença durante 0 ano inteiro sugere que os eqüinos ingerem a planta durante todo 0 ano, independente da disponibilidade de forragem. $C$. retusa em crescimento é palatável para eqüinos, que comem a planta desde a fase de muda até quando está com aproximadamente 12 a $18 \mathrm{~cm}$ (Rose et al. 1957a). Na região semi-árida C. retusa encontra-se em crescimento exatamente no período de chuvas, onde normalmente existe pasto para os animais. No entanto, não se pode descartar que haja uma maior ingestão da planta em épocas menos chuvosas, principalmente nas áreas irrigadas, onde a planta é encontrada em todas as fases de crescimento. Os animais adoecem posteriormente em períodos variáveis após a ingestão, devido ao efeito progressivo da lesão. Sabe-se que a intoxicação crônica por alcalóides pirrolizidínicos em eqüinos manifesta-se tipicamente como uma hepatopatia progressiva que se desenvolve num tempo variável após ou durante a ingestão de doses tóxicas (Cheeke 1998, Denham 2002). Considerando esses fatos é evidente a necessidade de se evitar o pastoreio de eqüinos em áreas invadidas por $\mathrm{C}$. retusa, independente da época do ano. Na Austrália a incidência parece ser sazonal, com os animais ingerindo a planta nos meses chuvosos (janeiro, fevereiro e março) e adoecendo num período variável de 3 a 6 meses após a ingestão. Em áreas onde a incidência é particularmente alta, um apreciável número de casos ocorre no período seco, de novembro a dezembro (Rose et al. 1957a). Na llha de Páscoa (Chile) a intoxicação por Crotalaria spp em eqüinos é sazonal, ocorrendo à maioria dos casos no verão (dezembro a fevereiro), período em que o pasto geralmente é seco (Narlesky 1999, Arzt \& Mount 1999). Segundo Peckham et al. (1974) e Hooper \& Scanlan (1977), a ingestão de Crotalaria sp ocorre quando há escassez de pastagem ou quando há a contaminação de alimentos ou ração pela planta ou pelas sementes. È importante salientar, também, que eqüinos sob condições de estresse metabólico ou nutricional e na gravidez apresentam mais facilmente a doença (Curran et al. 1996).

Um fato que chama a atenção, levando-se em consideração a igual susceptibilidade de bovinos e eqüinos a intoxicação por alcalóides pirrolizidinicos (Cheeke 1998), é a maior freqüência da intoxicação em eqüinos do que em bovinos na região semi-árida. Durante o período de 1996 a 2003 foram 
observados 23 casos em eqüinos e somente 3 em bovinos (Nobre et al. 2004). Considerando a maior população de bovinos e a aparentemente igual susceptibilidade destas espécies à intoxicação por AP, parece evidente que a maior freqüência em eqüinos se deve a maior palatabilidade da $C$. retusa para eqüinos do que para os bovinos. Na Ilha de Páscoa ocorrem surtos de intoxicação por C. grahamiana com incidência da doença tanto em eqüinos quanto em bovinos, embora os autores não quantifiquem os casos (Arzt \& Mount 1999). Outro fator importante a se levar em consideração é o não aparecimento da doença de forma espontânea em asininos, já que esta espécie apresentou a doença de forma experimental. No semi-árido existe uma população considerável de asininos e muitos são criados soltos no pasto. Considerando que na região há mais asininos de que eqüinos, uma possível causa desta diferença na ocorrência da doença é que os asininos não ingerem $C$. retusa. No entanto, deve-se considerar também a possibilidade de que os asininos não tenham acesso a planta, já que os jumentos se encontram, geralmente, em áreas de pastos menos nobres, onde não se observa a planta. A intoxicação não tem sido observada em mulas, o que possivelmente esteja associado, também, as possibilidades de ingestão da planta. Segundo Rose et al. (1957a) a doença em mulas e asininos ocorre ocasionalmente em áreas severamente afetadas. Os autores descrevem poucos casos em mulas e um caso em jumento.

O curso clínico da intoxicação por AP é variável, podendo ser de poucas semanas a meses. Na Austrália foi observado um eqüino com sinais clínicos intermitentes durante 18 meses (Rose et al. 1957a). Os animais com intoxicação natural no semi-árido apresentaram curso clínico variando entre 5 a 20 dias. Um animal apresentou sinais clínicos intermitentes durante 40 dias. 0 animal pode exibir a forma aguda da doença ao consumir plantas contendo AP em grande quantidade por um curto período de tempo ou a forma crônica com ingestão esporádica de pequenas quantidades da planta por um período prolongado (Curran et al. 1996), porém a forma aguda da doença é raramente vista em condições naturais (Bull 1961). Normalmente pode ocorrer um período de três a cinco meses entre o consumo da planta e o desenvolvimento dos sinais clínicos da doença (Curran et al. 1996), porém, um estudo clinico-patológico da toxicose por Senecio jacobaea em pôneis evidenciou dois padrões clínicos da progressão da doença: um processo de hepatopatia crônica com morte em 6 a 22 semanas (2 a 5 meses); e um processo de doença crônica retardada, onde os animais permanecem clinicamente normais até antes da morte em 38 a 58 semanas (9 a 14 meses). Os autores advertem que nestes casos tardios é necessário que os veterinários fiquem atentos porque os animais apresentam-se normais, enquanto que a hepatopatia progressiva está ocorrendo (Craig et al. 1991). Às vezes os animais apresentam recuperação quando retirados do pasto contendo plantas com AP (Gorder 2000). Porém na maioria das vezes, quando os sinais clínicos da toxicose por AP aparecem, os danos hepáticos são irreversíveis, havendo poucas exceções, onde os animais sobrevivem e apresentam melhoras na estrutura e nas funções hepática (Craig et al. 1991). É impor- tante que estes animais que sobrevivem sejam acompanhados periodicamente com exames de bioquímicos e biopsia hepática (Mendel et al. 1988). As diferentes respostas ou resistência individual dos animais as pirrolizidinas podem refletir: a detoxificação bacteriana no trato gastrintestinal; a taxa de conversão, no fígado, dos AP a pirróis tóxicos; e a capacidade anti-oxidativa individual do animal. A quantidade de AP ingerida na alimentação também é importante (Craig et al. 1991).

Os sinais clínicos e os aspectos patológicos apresentados pelos animais intoxicados naturalmente e experimentalmente são consistentes com as descrições publicadas nas intoxicações de eqüinos por Crotalaria spp (Gibbons et al. 1953, Rose et al. 1957a,b, Gardiner et al. 1965, Arzt \& Mount, 1999, Nobre et al. 1994, Denham 2002) e outras plantas contendo alcalóides pirrolizidinicos (Tennant et al. 1972, Seaman 1978, Knight et al. 1984, Gava \& Barros 1997, Creeper et al. 1999, Gorder 2000, Radostits et al. 2000) e com as toxicoses crônicas por pirrolizidinas em outras espécies animais (Peckham et al. 1974, McGrath \& Duncan, 1975, Norton \& O'Rourke 1979, Barri \& Adam 1981, Barri \& Adam 1984, Barri et al. 1988, Winter et al. 1990, Alfonso et al. 1993).

O quadro clínico-patológico apresentado pela maioria dos animais intoxicados naturalmente e experimentalmente é consistente com o de uma insuficiência hepática. A insuficiência hepática ocorre quando $70 \%$ ou mais da capacidade funcional do fígado é perdida (Tennant 1997), o que ocorre quando há perda de $80 \%$ a $90 \%$ do parênquima, podendo ser visto, tanto em hepatopatias tóxicas agudas quanto crônicas (Kelly 1993). Em um estudo para avaliar testes bioquímicos como indicadores de doença hepática subclínica em eqüinos expostos a toxicose por AP, verificou-se que a atividade da gama glutamiltransferase (GGT) no soro é um teste eficiente para caracterizar a doença subclínica nos eqüinos. A elevação dos níveis de GGT no soro sangüíneo tem um alto grau de especificidade para danos hepáticos. A GGT normalmente está limitada ao reticulo endoplasmático liso, onde o sistema de oxidase mista é ativo. Os AP são ativados por este sistema, onde causam danos e ocorre a liberação da GGT no soro (Curran et al. 1996). Em pôneis intoxicados experimentalmente com Senecio jacobaea a GGT foi o teste enzimático mais seguro para indicar o começo e a continuidade das alterações hepáticas (Craig et al. 1991). A elevação desta enzima foi documentada também em eqüinos com intoxicação natural e experimental por Senecio jacobaea (Giles 1983, Garret et al. 1984, Gorder 2000), Senecio vulgaris (Gulick et al. 1980, Lessard et al. 1986, Mendel et al. 1988) e Cynoglossum officinale (Knight et al. 1984). É importante citar que apesar de ser considerado um bom teste para avaliar a lesão hepática induzida por AP, nem todos os animais que apresentam aumento de GGT desenvolve sinais clínicos da doença (Giles 1983). Em alguns casos a GGT pode apresentar queda e retornar a valores de antes da exposição do animal aos AP (Craig et al. 1991). Esta queda foi interpretada por Lessard et al. (1986) como um bom indicador no prognóstico. Segundo Craig et al. (1991) é interessante monitorar os animais sobreviventes a intoxicação por AP com testes enzimáticos. Quando for observado aumento nas enzimas, 
principalmente GGT deve-se fazer uma biopsia hepática para verificar o grau das lesões hepáticas. A fosfatase alcalina (FA) também foi analisada nos eqüinos com intoxicação por C. retusa no semi-árido. Nos animais que foram dosados houve um aumento marcante da mesma. Esta enzima apesar de não ser hepato-específica, aumenta nos casos de danos hepáticos em decorrência de sua liberação na superfície sinusoidal dos hepatócitos, bem como na regurgitação das iso-enzimas biliares nos casos de colestase. Nas toxicoses por AP ocorrem ambas situações (Craig et al. 1991).

As principais lesões observadas no fígado dos animais intoxicados naturalmente e experimentalmente confirmam 0 que foi descrito por diversos autores que registraram hepatopatias causadas por plantas contendo alcalóides pirrolizidinicos, incluindo megalocitose, fibrose periportal (Gibbons 1953, Rose et al. 1957a,b, Gardiner et al. 1965, Muth 1968, Knight et al. 1984, Kelly 1993, Nobre et al. 1994, Arzt \& Mount 1999), hiperplasia (Knight et al, 1984, Arzt \& Mount 1999) e proliferação de células dos ductos biliares (Gibbons 1953, Gardiner et al. 1965, Muth 1968, Kelly 1993, Nobre et al. 1994), hemorragia periacinar e necrose hepatocelular (Sanchez et al. 1993, Kelly 1993, Arzt \& Mount 1999) e nos casos agudos ou subagudos, necrose centrolobular com hemorragia (Rose et al. 1957b, Muth 1968). Os alcalóides pirrolizidinicos são principalmente hepatotóxicos e após absorção no trato alimentar são metabolizados no fígado e convertidos a derivados pirrólicos altamente reativos, os quais provocam lesões nos hepatócitos (Mattocks et al. 1990). A megalocitose está relacionada a um efeito antimitótico, não por uma inibição da síntese de DNA e sim por uma síntese continuada de nucleoproteínas associadas a uma inibição da mitose (Kelly 1993). Esta lesão parece ser o resultado de uma ação combinada dos AP nos hepatócitos, um processo regenerativo, seguido de injuria as células do parênquima e uma ação antimitótica dos metabólitos pirrólicos dos AP, principalmente dos pirróis éster no retículo endoplasmático (Knight \& Walter 2001). Segundo Prakash et al. (1999) os AP induzem megalocitose devido a danos no DNA, conduzindo uma mutação nos genes reguladores do ciclo celular. A subseqüente regulação alterada do ciclo celular é resultante de uma superexpressão da proteína rum (mitose de replicação incompleta). As células são levadas a interromperem a fase G2/M do ciclo celular e são submetidas a uma fase $S$ adicional sem mitose interveniente. Como as células não se dividem e continuam a sintetizar DNA, aumentam de tamanho e morrem sendo substituídos por tecido fibroso ou por nódulos regenerativos. Na megalocitose 0 volume da célula afetada pode estar aumentado em mais de 20 vezes. Ao mesmo tempo em que se desenvolve a megalocitose, ocorre fibroplasia e proliferação de células dos ductos biliares na tríade portal (Kelly 1993). As hemorragias centrolobulares a mediozonais observadas na maioria dos animais não refletem uma forma aguda da doença, pois não traduzem necrose hemorrágica vista na intoxicação aguda por AP e sim hemorragias decorrentes, provavelmente, da diminuição na síntese dos fatores da coagulação decorrentes da insuficiência hepática (Allen 1963) e/ou da própria ação da monocrotalina nas células do endotélio sinusoidal (Yee et al. 2003). Dois eqüinos apresentaram necrose hemorrágica, o que sugere uma lesão aguda, porem também foram verificadas nesses animais, outras alterações que caracterizam um quadro crônico da intoxicação, como discreta fibrose portal e periportal e discreta hepatomegalocitose. Segundo Rose et al. (1957a) estes casos refletem uma lesão subaguda. Os autores acreditam que nestas situações o animal apresenta lesões produzidas em exposição anterior a AP, sobrepostas com lesões agudas produzidas por uma exposição recente, as quais foram suficientes para induzirem a doença e morte do animal. Os mesmos autores registraram um caso agudo natural e outro experimental em eqüinos na Austrália. Em outro caso de patologia sugestiva de intoxicação aguda por AP em eqüino registrado por Curran et al. (1996), as lesões hepáticas caracterizaramse por severa congestão centrolobular e hemorragia com necrose de hepatócitos e agregação focal de células inflamatórias, ruptura da arquitetura e formação de grandes hepatócitos vacuolizados com citoplasma espumoso, sem megalocitose.

Patologias hepáticas difusas graves geralmente são acompanhadas de manifestações clínicas típicas de insuficiência hepática, tais como icterícia, encefalopatia hepática e fotosenssibilização hepatógena (Kelly 1993, Tennant 1997). No presente relato, apenas alguns animais apresentaram icterícia, um animal apresentou fotossensibilização e os sinais clínicos neurológicos típicos de disfunção hepática foram observados em todos os animais. Embora os sinais neurológicos tenham sido verificados em todos os animais, as lesões do encéfalo, caracterizadas pela presença de astrócitos Alzheimer tipo II só foram verificadas em cinco eqüinos e no asinino que ingeriu $5 \mathrm{~g} / \mathrm{kg}$ da C. retusa. Em um eqüino (№2) não foi encaminhado encéfalo pelo veterinário e os outros dois apresentavam diferentes graus de autólise. Em muitos casos de intoxicação por $C$. retusa os sinais clínicos do sistema nervoso têm levado os veterinários de campo ao diagnóstico presuntivo de raiva ou encefalomielite eqüina. Sinais clínicos de encefalopatia hepática também foram observados em eqüinos intoxicados por Crotalaria retusa na Austrália (Rose et al. 1957a,b), por outras espécies de Crotalaria (Nobre et al. 1994, Arzt \& Mount 1999) e nas intoxicações de eqüinos por outras plantas contendo alcalóides pirrolizidinicos (Giles 1983, Knight et al. 1984, Gava \& Barros 1997). Eqüinos com encefal opatia hepática apresentam uma notável disparidade entre a severidade dos sinais clínicos e a sutileza das alterações patológicas no cérebro, estando estas limitadas à presença de astrócitos isolados, em pares ou múltiplos, com núcleos vesiculares, aumentados e claros, na substância cinzenta, sendo referidos como astrócitos Alzheimer tipo II. São encontrados em maior numero no córtex, núcleos basais e hipocampo, como satélites neuronais, no neuropilo ou isolados (Summers et al. 1995). A disfunção neurológica é causada principalmente por hiperamonemia devido ao fígado lesado não metabolizar a amônia absorvida pelo intestino (Kelly 1993). A amônia no sistema nervoso central é metabolizada pela glutamina dos astrócitos, a qual por si própria pode ser neurotóxica (Summers et al. 1995). 
Pôneis intoxicados por Senecio jacobaea apresentam como um dos principais aspectos patológicos secundários uma impactação gástrica, com o estômago aumentado, contendo feno seco, com ruptura na curvatura maior e marcada hemorragia no local da ruptura (Milne et al. 1990). Os eqüinos necropsiados com intoxicação natural e o eqüino intoxicado experimentalmente por $\mathrm{C}$. retusa não mostraram evidencias de impactação gástrica, sendo verificado na parede do estomago e intestinos apenas edema e no animal intoxicado experimentalmente, conteúdo intestinal mais fluido. Os edemas, principalmente cavitários observados na maioria dos animais foram, também, registrados por outros autores na intoxicação por Crotalaria em eqüinos e outras espécies animais (Gibbons et al. 1953, Figueredo et al. 1987, Torres et al. 1997, Arzt \& Mount 1999), bem como na intoxicação por outras plantas contendo AP em eqüinos e bovinos (Muth 1968) e têm sido atribuídos à diminuição da síntese protéica pelo fígado lesado ou a hipertensão portal por lesão hepática crônica (Peterson \& Cuvenor 1983, Kelly 1993).

As lesões pulmonares resultantes da intoxicação por AP são bem descritas em ratos e caracterizam-se basicamente por alterações no endotélio de vasos pulmonares, vasculite pulmonar proliferativa, hipertensão pulmonar e cor pulmonale (Ghodsi \& Will 1981, lto et al. 2000). Pneumonia intersticial, alterações degenerativas e proliferativas em capilares e arteríolas, foram descritas em suínos intoxicados por Crotalaria spp (Peckham et al. 1974) e Crotalaria spectabilis (Torres et al. 1997). Foram descritas também, broncopneumonia e bronquite crônica em suínos intoxicados por $\mathrm{C}$. spectabilis (Souza et al. 1997). Metabólitos pirrólicos primários de vida especialmente longa podem alcançar os pulmões e o coração, onde causam danos as macromoléculas destes órgãos (Prakash et al. 1999). Alguns autores descreveram lesões pulmonares em eqüinos intoxicados por plantas contendo alcalóides pirrolizidinicos. Gardiner et al. (1965) e Nobre et al. (1994) observaram alveolite fibrosante difusa, com espessamento de septos interalveolares, edema e infiltrado inflamatório mononuclear, principalmente macrófagos espumosos. Nobre et al. (1994) ainda observaram alvéolos com áreas cobertas por epitélio cuboidal, enfisema alveolar e hiperplasia do epitélio dos brônquios. Curran et al. (1996) observaram enfisema pulmonar em um eqüino com lesões crônicas por AP. As lesões pulmonares observadas nos eqüinos com intoxicação natural e no eqüino com intoxicação experimental relatados neste trabalho diferem das observadas por esses autores e consistiram praticamente de edema e congestão. No Eqüino 3, algumas células do endotélio das artérias pulmonares visualizadas no pulmão apresentaram-se maiores sugerindo megalocitose. Nos Eqüinos 1, 3, 5, 6 e 8 havia discreto espessamento da parede dos vasos e observou-se discreta hiperplasia da parede de bronquíolos no eqüino 8. Essas alterações pulmonares poderiam ter sido causadas pela ação dos metabólitos pirrólicos derivados da monocrotalina presente em $C$. retusa. $O$ espessamento da parede de vasos também foi observado por Gardiner et al. (1965), que o atribuíram a um aparente aumento das células endoteliais e a uma reação fibroblastica intersticial. No entanto, as lesões visualizadas nos eqüinos neste trabalho são discretas e não causaram sinais clínicos. Apenas um animal apresentou sinais clínicos respiratórios, porem foi observado pneumonia granulomatosa provavelmente associado ao Rhodococus equi. Segundo Kelly (1993), não deveria ser assumido que todos os AP hepatotóxicos produzem lesões pulmonares ou que todas as espécies animais sejam igualmente susceptíveis aos danos pulmonares. Gardiner et al. (1965) comentam não ter visto alterações pulmonares em eqüinos com "Kimberley horse disease" resultante da intoxicação por C. retusa e relacionam algumas espécies de Crotalaria responsáveis por desenvolver lesões pulmonares em eqüinos (C. crispata, $C$. dura e C. globifera), sendo as duas ultimas implicadas na produção da doença pulmonar denominada de "Jaagsiekte disease" na África do Sul. Pitt \& Mckenzie (2002) afirmam que C. mitchellii também provoca lesões pulmonares semelhantes.

As lesões renais decorrentes da intoxicação por alcalóides pirrolizidinicos são bem caracterizadas em suínos e consistem, principalmente, de nefrite intersticial, alargamento do tufo glomerular por aumento da matriz mesangial (Peckham, et al. 1974, McGrath \& Duncan, 1975, Torres et al. 1997), hipertrofia e cariomegalia (megalocitose) de células dos túbulos proximais e presença de material protéico e cilindros hialinos na luz dos túbulos (Muth 1968, Peckham et al. 1974, McGrath \& Duncan 1975, Souza et al. 1997, Torres et al. 1997). Megalocitose das células dos túbulos renais foi vista também em suínos intoxicados por Senecio jacobaea (Harding et al. 1964). Alterações vasculares como hialinização de arteríolas, tumefação de células endoteliais e proliferação da adventícia, com espessamento de parede de vasos também foram descritas (Peckham et al. 1974, Torres et al. 1997). Em eqüinos foram descritas nefrose tubular moderada, vacuolização de células tubulares, descamação de células epiteliais (Nobre et al. 1994), glomerulite proliferativa e megalocitose de células do epitélio dos túbulos proximais (Curran et al. 1996). As alterações observadas nos rins dos animais com intoxicação espontânea descritas neste trabaIho foram discretas e 0 que mais a chamou atenção foi 0 aumento de tamanho das células do epitélio tubular, vistas principalmente nos túbulos proximais de três animais, e 0 espessamento da parede de vasos observada principalmente no Eqüino 8, que exibia, também, discreta tumefação de células endoteliais. A megalocitose nas células dos túbulos renais é freqüente em suínos e rara em outras espécies animais. A maior freqüência de megalocitose em suínos pode ser atribuída a uma maior excreção do metabólito pirrólico na urina ou a uma maior concentração do metabólito nos túbulos renais dos suínos (Peterson \& Cuvenor 1983). Sabese que os alcalóides pirrolizidinicos são hidrolisados no fígado, inicialmente a éster pirrólico e posteriormente a álcool pirrólico, sendo estes últimos excretados na urina (Bull et al. 1968).

Prejuízos econômicos são experimentados pelos criadores de eqüinos na região semi-arida em função das condições climáticas e de manejo alimentar dos animais nas propriedades onde se observa $C$. retusa em meio às escassas áreas de pastagem. Acredita-se que esses prejuízos não se 
restrinjam somente a perda de animais, mas também com relação à produtividade dos animais, devido à lesão hepática induzida pelas pirrolizidinas, principalmente porque os animais com doença subclínica são intolerantes a exercícios e perdem peso.

\section{REFERÊNCIAS}

Allen J. R. 1963. Crotalaria spectabilis toxicity studies in turkeys. Avian Dis. 7: 318-324.

Arzt J. \& Mount M. 1999. Hepatotoxicity associated with pyrrolizidine alkaloid (Crotalaria spp) ingestion in a horse on Easter Island. Vet. Human. Toxicol. 41: 96-99.

Azevedo Junior J.M., Nobre V.M.T., Tabosa I.M., Riet-Correa F., Cunha E.V.L., Silva M.S. \& Barbosa Filho J.M. 2000. Monocrotalina, um alcalóide pirrolizidínico de Crotalaria retusa como provável responsável pelas intoxicações observadas em eqüídeos e ovinos na Paraíba. 16o Simpósio de Plantas Medicinais do Brasil, Recife, p.179. (Resumo)

Barbosa Filho J.M., Cunha E.V.L., Cornélio M.L., Dias C.S. \& Gray A.I. 1997. Cissaglaberrimine, an aporphine alkaloid from Cissampelos glaberrima. Phytochem. 44: 959-961.

Barri M. E. S. \& Adam S. E. I. 1981. The toxicity of Crotalaria saltiana to calves. J. Comp. Path. 91: 621-627.

Barri M. E. S. \& Adam S. E. I. 1984. Effects of Crotalaria saltiana on Nubian Goats. Vet. Human. Toxicol. 26: 476-480.

Barri M. E. S., Adam S. E. I. \& Omer O. H. 1988. Toxic effects of Crotalaria saltiana in mice. Vet. Human. Toxicol. 30: 429-431.

Bull L.B. 1961. Liver diseases in livestock from intake of hepatotoxic substances. Aust. Vet. J. 37: 126-130.

Bull L. B., Culvenor C. C. J. \& Dick A. T. 1968. The pyrrolizidine alkaloids. Their chemistry, pathogenicity and biological properties. North-Holland Publ. 293p.

Cheeke, P.R. 1998. Natural Toxicants in Feeds, Forages, and Poisonous Plants. 2nd ed. Interstate, Danville, Illinois. $479 \mathrm{p}$.

Craig A.M., Pearson E.G., Meyer C. \& Schmitz A. 1991. Clinicopathologic studies of tansy ragwort toxicosis in ponies: sequential serum and histophatological changes. Equi. Vet. Sci. 11: 261-281.

Creeper J.H., Mitchell A.A. Jubb T.F. \& Colegate S.M. 1999. Pyrrolizidine alkaloid poisoning of horses grazing a native heliotrope (Heliotropium ovalifolium). Aust. Vet. J. 77: 401-402.

Curran J.M., Sutherland R.J. \& Peet R.L. 1996. A screening test for subclinical liver disease in horses affected by pyrrolizidine alkaloid toxicosis. Aust. Vet. J.. 74: 236-240.

Dantas A. F. M., Nobre V. M. T. \& Tabosa I. M. 1999. Intoxicação aguda por Crotalaria sp (Leguminosae) em ovinos na Paraíba, Brasil - relato de caso. $9^{\circ}$ Enapave, Belo Horizonte, p. 89. (Resumo)

Denham A. 2002. Pyrrolizidine Alkaloids. Matéria Médica. Disponivel em: www. nimh.btinternet.co.vk/ejhm/matéria.htm.

Figueredo M.L.A., Rodriguez J. \& Alfonso H.A. 1987. Patología de la intoxication experimental aguda por Crotalaria retusa y Crotalaria spectabilis em pollos. Revta Cubana Cienc. Vet. 18: 63-71.

Gardiner M. R., Royce R. \& Bokor A. 1965. Studies on Crotalaria crispata, a newly recognised cause of Kimberley horse disease. J. Comp. Path. Bact. 89: 43-53.

Garret B. J., Holtan W., Cheeke P.R., Schmitz J.A. \& Rogers Q.R. 1984. Effects of dietary supplementation with butylated, cysteine, and vitamins $B$ on tansy ragwort (Senecio jacobaea) toxicosis in ponies. Am. J. Vet. Res. 45: 459-464.

Gava A. \& Barros C.S.L. 1997. Senecio spp poisoning of horses in southern Brazil. Pesq. Vet. Bras. 17: 36-40.

Ghodsi F. \& Will J. A. 1981. Changes in pulmonary structure and function induced by monocrotaline intoxication. Am. J. Physiol. 9: H149-H155.
Gibbons W.J., Durr E. H. \& Cox S. A. 1953. An outbreak of cirrosis of the liver in horses. North. Am. Vet. 34: 556-558.

Giles C.J. 1983. Outbreak of ragwort (Senecio jacobea) poisoning in horse. Equine Vet. J. 15: 248-250.

Gorder V.L. 2000. Tansy ragwort poisoning in a horse in southern Ontario. Can. Vet. J. 41: 409-410.

Gulick B.A., Irwin K.M., Charles W. \& Qualls JR. 1980. Effect of pyrrolizidine alkaloid-induced hepatic disease on plasma amino acid patterns in the horse. Am. J. Vet. Res. 41: 1894-1898.

Harding J.D.J., Lewis G., Done J.T. \& Allcroft R. 1964. Experimental poisoning by Senecio jacobaea in pigs. Path. Vet. 1: 204-220.

Hooper P.T. \& Scalan B.V. 1977. Crotalaria retusa poisoning of pigs and poultry. Aust. Vet. J. 53:109-114.

Ito K.M., Sato M., Ushijima K., Nakai M. \& Ito K. 2000. Alterations of endothelium and smooth muscle function in monocrotaline-induced pulmonary hypertensive arteries. Am. J. Heart Circ. Physiol. 279: H1786H1795.

Kelly W. R. 1993. The liver and biliary system, 319-404. In: Jubb K.V.F., Kennedy P.C. \& Palmer N. (ed.) Pathology of Domestic Animals. Vol. 2. $4^{\text {th }}$ ed. Academic Press, San Diego.

Knight A.P., Kimberling C.V. \& Stermitz F.R. 1984. Cynoglossum officinale (hound's-tongue), a cause of pyrrolizidine alkaloid poisoning in horses. J. Am. Vet. Med. Assoc. 185: 647-650.

Knight A.P. \& Walter R.G. 2001. A Guide to Plant Poisoning of Animals in North America. New Media, Teton. 578 p.

Lemos R.A.A. \& Barros C.S.L. 1998. Intoxicação por Crotalaria sp, p.322-325. In: Lemos R.A. A. (ed.) Principais Enfermidades de Bovinos de Corte do Mato Grosso do Sul. Universidade Federal do Mato Grosso do Sul., Campo Grande.

Lessard P. Wilson W.D., Olander H.J., Rogers Q.R. \& Mendel V.E. 1986. Clinicopathologic study of horses surving pyrrolizidine alkaloid (Senecio vulgaris) toxicosis. Am. J. Vet. Res. 47: 1776-1780.

Mattocks A.R. \& Jukes R. 1990. Trapping and measurement of short-lived alkylating agents in a recirculating flow system. Chem. Biol. Interact. 761930.

McGrath J.P.M. \& Duncan J.R. 1975. Crotalaria spectabilis toxicity in swine: characterization of the renal glomerular lesion. J. Comp. Path. 85:185-194.

Medeiros R.M.T. 1994. Veiculação do principio tóxico da Crotalaria spectabilis (Roth) em leite de cabra e rata: uma avaliação toxicológica. Dissertação (Mestrado), Faculdade de Medicina Veterinária, Universidade de São Paulo, São Paulo. 142 p.

Mendel V.E., Witt M.R., Gitchell B.S., Gribble D.N., Rogers Q.R., Segall H.J. \& Knight H.D. 1988. Pyrrrolizidine alkaloid-induced liver disease in horse: An early diagnosis. Am. J. Vet. Res. 49:572-578.

Milne E.M., Pogson D.M. \& Doxey D.L. 1990. Secondary gastric impactation associated with ragwort poisoning in three ponies. Vet. Rec. 19:502-504.

Muth, O.H. 1968. Tansy ragwort (Senecio jacobaea), a potential menace to livestock. J. Am. Vet. Med. Assoc. 153: 310-312.

Narlesky L. 1999-2000. MPVM Graduate Tackles Mysterious and Deadly Animal IIIness on Easter Island. Vet. Med. News, Fall/Winter, 16:1-2.

Nobre D., Dagli M.L.Z. \& Haraguchi M. 1994. Crotalaria juncea intoxication in horses. Vet. Human. Toxicol. 36: 445-448.

Nobre V.M.T., Riet-Correa F., Dantas A.F.M., Tabosa I.M., Medeiros R.M.T. \& Barbosa Filho J. M. 2004. Intoxication by Crotalaria retusa in ruminants and eqüidae in the state of Paraíba, northeastern Brazil, p. 275-278. In: Plant Poisoning and related Toxins. CAB International, Glasgow, UK.

Norton J.H. \& O'Rourke P.K. 1979. Toxicity of Crotalaria goreensis for chickens. Aust. Vet. J. 55:173-174.

Paio R.C. 2003. Ervas Medicinais: Confrei. Disponível em: www.ervasmed.el/ 420.html.

Peckham J.C., Sangster L.T. \& Jones Jr. O.H. 1974. Crotalaria spectabilis poisoning in swine. J. Am. Vet. Med. Assoc. 165: 633-638. 
Peterson J.E. \& Culvenor C.C.J. 1983. Hepatotoxic pyrrolizidine alkaloids, p. 637-671. In: Keeler R.F., TU A.T. (ed.) Handbook of Natural Toxins. Vol. 1. Marcel Dekker, New York.

Pitt D. \& Mckenzie R. 2002. Jaagsiekte in Horses. Queensland Government. Disponível em: www.qld.gov.au/news/371.html.

Prakash A.S., Perera, T.N., Reilly P.E.B. \& Seawright A.A. 1999. Pirrolizidine alkaloids in human diet. Mutat. Res. 443: 53-67.

Radostits O.M., Blood D.C. Gay C.C. \& Hinchcliff K.W. 2000. Veterinary Medicine: a textbook of the diseases of cattle, sheep, pigs, goats and horses. Chap. 32. Diseases caused by toxins in plants: pyrrolizidine alkaloid poisoning. 9th ed. W.B. Saunders, London., p. 1661-1665.

Rose A.L., Gardner C.A., Mcconnell J.D. \& Bull L.B. 1957a. Field and experimental investigation of "walk about" disease of horses (Kimberley horse disease) in Northern Australia: Crotalaria poisoning in horses. Part 1. Aust. Vet. J. 33: 25-33.

Rose A.L., Gardner C.A., Mcconnell J.D. \& Bull L.B. 1957b. Field and experimental investigation of "walk about" disease of horses (Kimberley horse disease) in Northern Australia: Crotalaria poisoning in horses. Part II. Aust. Vet. J. 34: 49-62.

Sanchez A.L.M., Figeurdo A. \& Gomez B.C. 1993. Intoxication due Crotalaria retusa and C. spectabilis in chickens and geese. Vet. Hum. Toxicol. 35: 539.

Seaman J.T. 1978. Pyrrolizidine alkaloid poisoning of horse. Aust. Vet. J. 54: 150.

Souza A.C., Hatayde M.R. \& Bechara G.H. 1997. Aspectos patológicos da into- xicação de suínos por sementes de Crotalaria spectabilis (Fabaceae). Pesq. Vet. Bras. 17:12 - 18.

Summers B.A., Cummings J.F. \& De La Hunta A. 1995. Veterinary Neuropathology. Cap. 5: Degenerative diseases of the central nervous system - metabolic and circulatory disorders. Editora, local ?, p. 208-214.

Tennant B.C., Evans C.D.Kaneko J.J. \& Schalm O.W. 1972. Hepatic failure in the horse. Med. Veter. Prat. 11: 40-42.

Tokarnia C. H. \& Döbereiner J. 1983. Intoxicação experimental por Crotalaria anagyroides (Leg. Papilionoideae) em bovinos. Pesq. Vet. Bras. 3: 115-123.

Torres M.B.A.M., Sales M.W.S., Headley S.A. \& Barros C.S.L. 1997. Intoxicação experimental por sementes de Crotalaria spectabilis (Leguminosae) em suínos. Ciência Rural, Santa Maria, 27:307-312.

Williams M.C. \& Molyneux R.J. 1987. Occurrence, concentration and toxicity of pyrrolizidine alkaloids in Crotalaria seeds. Weed Science 35: 476-481.

Winter H., Seawright A.A., Mattocks A. R., Jukes R., Tshewang A.R. \& Gurung B.). 1990. Pirrolizidine alkaloid poisoning in yaks. First report and confirmation by identification of sulphurbound pyrrolic metabolites of the alkaloids in preserved liver tissue. Aust. Vet. J. 67: 411-412.

Yee S.B., Ganey P.E. \& Roth R. 2002. The role of Kupffer cells and TNF-á in monocrotaline and bacterial lipopolysaccharide-induced liver injury. Toxicol. Sci. 71: 124-132.

Yee S.B. 2003. The coagulation system contributes to synergistic liver injury from exposure to monocrotaline and bacterial lipopolysaccharide. Toxicol. Sci. 74: 457-69. 